\title{
Vertical distribution and temporal stability of soil water in 21-m profiles under different land uses on the Loess Plateau in China
}

\author{
Yunqiang Wang ${ }^{\mathrm{a}, \mathrm{b}, \mathrm{c}, *}$, Wei Hu ${ }^{\mathrm{d}}$, Yuanjun Zhu ${ }^{\mathrm{b}}$, Ming'an Shao ${ }^{\mathrm{c}}$, Shun Xiao ${ }^{\mathrm{e}}$, Chencheng Zhang ${ }^{\mathrm{b}}$ \\ a State Key Laboratory of Loess and Quaternary Geology, Institute of Earth Environment, Chinese Academy of Sciences, Xi'an, Shaanxi 710061, China \\ ${ }^{\mathrm{b}}$ State Key Laboratory of Soil Erosion and Dryland Farming on the Loess Plateau, Institute of Soil and Water Conservation, \\ Chinese Academy of Sciences \& Ministry of Water Resources, Yangling 712100, China \\ ${ }^{\mathrm{c}}$ Key Laboratory of Ecosystem Network Observation and Modeling, Institute of Geographic Sciences and Natural Resources Research, \\ Chinese Academy of Sciences, Beijing 100101, China \\ ${ }^{\mathrm{d}}$ University of Saskatchewan, Department of Soil Science, Saskatoon, SK S7N 5A8, Canada \\ e Shaanxi Meteorological Bureau, Xi'an 710014, China
}

\section{A R T I C L E I N F O}

\section{Article history:}

Received 22 December 2014

Received in revised form 5 May 2015

Accepted 7 May 2015

Available online 14 May 2015

This manuscript was handled by Corrado

Corradini, Editor-in-Chief, with the

assistance of Renato Morbidelli, Associate

Editor

\section{Keywords:}

Deep soil

Land use

MABE

Temporal stability

Most temporally stable depth

The Chinese Loess Plateau

\section{S U M M A R Y}

Deep soil-water content (SWC) plays a crucial role in water-limited terrestrial ecosystems, because plant roots can extract soil water from depths of $20 \mathrm{~m}$ or more. The distribution of soil water and its temporal variation in deep $(>5 \mathrm{~m})$ soil profiles are not completely understood, partly due to the time and labor needed for their determination. We examined the vertical distribution patterns and temporal stabilities of soil water in 21-m soil profiles for two years under four typical land use types in the Liudaogou watershed of the Chinese Loess Plateau (CLP). The SWCs exhibited considerable variability over both depth and time under farmland, natural grassland, planted grassland, and shrubland. The soil profile could be partitioned into an active layer $(0-2 \mathrm{~m})$ and a relatively stable layer $(2-21 \mathrm{~m})$ based on the amount of temporal change in SWC. The mean available soil water contents (AWCs) among the land use types in the depth-time domain differed significantly $(P<0.05)$, and followed the order: farmland $(7.1 \%)>$ natural grassland $(6.5 \%)>$ planted grassland $(5.7 \%)>$ shrubland $(4.9 \%)$. The mean available soil water storage for each 1 -m-depth $\left(A_{W} S_{1 \mathrm{~m}}\right.$ ) in the $0-21 \mathrm{~m}$ profile, in the time domain, ranged from 50.3 to $71.4 \mathrm{~mm}$ among the four land use types. Within the $21-\mathrm{m}$ profile, as the depths of sub-profiles increased from $3 \mathrm{~m}$ to $21 \mathrm{~m}$, the most temporally stable depths (MTSDs) of $\mathrm{AWS}_{1 \mathrm{~m}}$ tended to become deeper in a step-like manner, producing ranges of MTSDs of 3-18 m, 2-15 m, 2-9 m, and 3-20 m under farmland, natural grassland, planted grassland, and shrubland, respectively. The ability of the MTSDs to estimate the mean $\mathrm{AWS}_{1 \mathrm{~m}}$ in a soil profile was generally acceptable for each sub-profile, as indicated by the RMSD and RBIAS values obtained from a validation dataset, which ranged from 3.6 to $7.7 \mathrm{~mm}$ and from 0.07 to 0.13 , respectively, among the four land use types. The mean $\mathrm{AWS}_{1 \mathrm{~m}}$ within the 21 -m profile could, in general, be accurately estimated by measuring AWC to a depth of only $18 \mathrm{~m}$ based on the temporal stability analysis. Land use greatly affected the vertical distributions and temporal stabilities of the AWC in the deep soils. The knowledge obtained from this information is vital for the sustainable use of water resources, rational management of various land uses, and scientific determinations of soil water in deep soils on the CLP and possibly in other fragile ecosystems covered by deep soils around the world. (c) 2015 Elsevier B.V. All rights reserved.

\section{Introduction}

The soil-water content (SWC) of a profile plays an important role in the partitioning of available energy at the earth's surface

\footnotetext{
* Corresponding author at: State Key Laboratory of Loess and Quaternary Geology, Institute of Earth Environment, Chinese Academy of Sciences, Xi'an, Shaanxi 710061, China. Tel./fax: +86 2962336292.

E-mail address: wangyunq04@163.com (Y. Wang).
}

into sensible and latent heat, of rainfall into infiltration and runoff, and of plant production into above- and below-ground biomass (Heathman et al., 2003; Western et al., 2004). Therefore, SWC potentially affects many agricultural, hydrological, ecological, and meteorological processes such as runoff generation, soil erosion, solute transport, vegetation dynamics, evapotranspiration, drought dynamics, and soil desiccation (Chaney et al., 2015; Markewitz et al., 2010; Mendham et al., 2011; Wang et al., 2011; Western and Blöschl, 1999). 


$\begin{array}{ll}\text { Nomenclature } \\ \text { AWC } & \text { available soil-water content } \\ \text { AWC }_{1 \mathrm{~m}} & \text { AWC storage at each 1-m-depth } \\ \text { BD } & \text { bulk density } \\ \text { CLP } & \text { the Chinese Loess Plateau } \\ \text { CR } & \text { counting rate } \\ \text { CV } & \text { coefficient of variation } \\ \text { MABE } & \text { mean absolute bias error }\end{array}$

Increasingly, efforts have been made to understand SWC dynamics and related hydrological processes at a series of space and time scales around the world (Brocca et al., 2012; Han et al., 2012; Martínez-Fernández and Ceballos, 2003; Vereecken et al., 2014; Western and Blöschl, 1999; Western et al., 1998, 2002, 2004). Recently, Chaney et al. (2015) found that topography and soil types were the main drivers of spatial heterogeneity of SWC over the Little River Experimental Watershed in Georgia. Rosenbaum et al. (2012) pointed out that large variations in SWC spatial patterns in the topsoil were mainly related to meteorological conditions, while the SWC dynamics in the subsoil tended to diminish due to water redistribution processes and root water uptake. Markewitz et al. (2010) found that the contribution of simulated root water uptake was about $20 \%$ of water demand from depths of 2.5 to $5.5 \mathrm{~m}$ and about $10 \%$ from depths of 5.5 to $11.5 \mathrm{~m}$.

The importance of the role of water in deep soil, which may be used by roots in water-limited environments such as those in arid and semiarid regions and regions suffering from seasonal water shortages, has been recognized during the last 20 years (Nepstad et al., 1994). The maximum depletion depth of soil water, inferred to be a function of root water uptake, has been reported to be $18 \mathrm{~m}$ in an Amazonian forest (Davidson et al., 2011) and $21.5 \mathrm{~m}$ in a pine forest on the Chinese Loess Plateau (CLP) (Wang et al., 2009b). A good understanding of soil-water regimes in deep soil profiles (i.e., below $5 \mathrm{~m}$ ) is vital for evaluating the response of plant growth to global climate change, and especially the responses to extreme drought, but such information is scarce.

Soil water is characterized by high spatio-temporal variability at a wide range of scales, and is mainly controlled by topography, vegetation, solar radiation, soil properties, meteorological forcing, and the depth to the water table, as well as by their interactions (Chaney et al., 2015; Gómez-Plaza et al., 2001; Hu et al., 2011; Nyberg, 1996; Regalado and Ritter, 2006; Wang et al., 2012; Western and Blöschl, 1999). Therefore, the determination of SWC in the field is difficult, and it is more expensive, time consuming, and labor intensive to undertake for deep soil profiles. The techniques for determining SWCs have been systematically documented (Dobriyal et al., 2012; Vereecken et al., 2014). Some noncontact techniques such as those using physical models, remote sensing, and ground-penetrating radar (Albergel et al., 2008; Brocca et al., 2013; Corradini et al., 2000; Das and Mohanty, 2006; Dobriyal et al., 2012; Morbidelli et al., 2011, 2014; Steelman et al., 2012) have been successfully used to estimate SWCs at various spatial and temporal scales in different regions of the world. However, these methods generally need measurements of soil, plant, topographical, and/or atmospheric parameters in order to estimate and/or calibrate SWCs, and the accuracy greatly depends on an understanding of soil-water processes. Furthermore, the measurements of the required parameters always involve a greater effort (Hu and Si, 2014).

Temporal stability is defined as the time-invariant association between spatial location and statistical parameters of a given soil property (i.e., SWC) (Vachaud et al., 1985). Later, Kachanoski and de Jong (1988) expanded the definition of the stability of a given
MRD mean relative difference

MTSD the most temporally stable depth

RBIAS absolute bias relative to the mean

RMSD root mean square deviation

SWC soil-water content

$\theta \quad$ gravimetric soil-water content soil property over time as a description of the temporal persistence of the spatial pattern.

The temporal stability provides a useful insight when analyzing spatio-temporal patterns of SWC (Brocca et al., 2010; Hu et al., 2013; Martinez et al., 2013). Since the concept was first introduced by Vachaud et al. (1985), considerable interest has been generated in assessing the temporal stability of SWC or soil water storage at the plot (Brocca et al., 2009; Pachepsky et al., 2005), slope (Gao and Shao, 2012; Hu et al., 2010b; Jia et al., 2013), watershed (Brocca et al., 2010; Hu et al., 2010a), and regional scales (Martínez-Fer nández and Ceballos, 2003). The concept has also been successfully used to extrapolate measurements of soil moisture at temporally stable or "representative" points to larger areas (Brocca et al., 2010; Gao et al., 2013; Jacobs et al., 2004). The analysis of temporal stability was recently extended to estimate mean SWCs in adjacent or distant areas for which no data were available or the data were limited (Hu et al., 2013). These studies have enriched the understanding of the characteristics of SWC temporal stability at different spatial scales and under various site conditions related to climate, soil, vegetation, and topography around the world. However, most of these studies have focused on the horizontal temporal stability of SWC, with the exception of a very recent study that examined vertical SWC temporal stability in $3.8-\mathrm{m}$ soil profiles (Hu and Si, 2014). To our knowledge, the temporal stability of vertical SWC patterns in deeper soil profiles has not been addressed. In addition, the association between land use and the temporal stability of vertical distribution patterns of SWC is not clear.

The CLP is characterized by thick loessial deposits, severe soil erosion, and fragile ecosystems (Shi and Shao, 2000). The "Grain for Green" project launched in 1999 by the Chinese government has converted a high proportion of the farmland located in areas sensitive to erosion, such as those on steep slopes, to grassland, shrubland, or forest by planting perennial plants that generally have deep root systems (Wang et al., 2013). The widespread revegetation with perennial plants may potentially affect many ecological and hydrological processes on the CLP, which could necessitate further investigation of the processes involving deep soil and water, which occur below-ground, that generally mediate plant growth and ecosystemic stability, which occur above-ground. Ascertaining the patterns of soil water distribution dynamics to a depth that encompasses or extends beyond the entire rooting zone would help to identify the relationships between below- and above-ground processes on the CLP. In particular, investigating the spatial and temporal patterns of available soil water content (AWC) under different land use types is essential when evaluating the impact of land use change (e.g., under the "Grain for Green" project) on soil water regimes. In turn, the AWC data of deep soils may indicate how much water is available for the growth of the plants used in the re-vegetation projects.

Temporal stability analysis applied in the vertical direction can be used to estimate the mean available soil water storage at each 1-m-depth (hereafter, abbreviated to $\mathrm{AWS}_{1 \mathrm{~m}}$ ) for different deep sub-profiles $(0-3,0-4,0-5, \ldots, 0-21 \mathrm{~m})$ by using the $\mathrm{AWS}_{1 \mathrm{~m}}$ 
measurement made at the most temporally stable depth (MTSD). We hypothesize that land-use type, which is an important factor influencing soil-water conditions (Wang et al., 2012, 2009b; Yang et al., 2012), affects the characteristics of the temporal stability of $\mathrm{AWS}_{1 \mathrm{~m}}$ in the vertical direction. Therefore, the objectives of this study were: first, to examine the vertical distributions and dynamics of soil water (including SWC and AWC) to a depth of $21 \mathrm{~m}$ under four typical land use types (farmland, natural grassland, planted grassland, and shrubland) in the Liudaogou watershed in the wind-water erosion criss-cross region of the CLP; second, to assess and compare the temporal stability of $\mathrm{AWS}_{1 \mathrm{~m}}$ within the 21-m profiles under the four land use types; and finally, to estimate the mean $\mathrm{AWS}_{1 \mathrm{~m}}$ of the entire $21-\mathrm{m}$ soil profile and sub-profiles by measurements at MTSDs in order to ascertain a proper measurement depth for a profile-averaged $\mathrm{AWS}_{1 \mathrm{~m}}$ of deep sub-profiles. Our objectives are pertinent to a special issue published by the Journal of Hydrology that focused on SWC determinations at different scales (Corradini, 2014). This study, by expanding the measurement scale to deep $(21 \mathrm{~m})$ soil profiles, may add to our understanding about soil water dynamics and determinations in the vertical direction closely related to vegetation reconstruction in fragile ecosystems.

\section{Materials and methods}

\subsection{Site description}

The study was conducted in the Liudaogou watershed $\left(38^{\circ} 46^{\prime}-\right.$ $\left.38^{\circ} 51^{\prime} \mathrm{N}, 110^{\circ} 21^{\prime}-110^{\circ} 23^{\prime} \mathrm{E}\right), 14 \mathrm{~km}$ west of Shenmu County, Shaanxi Province, in the northern part of the CLP (Fig. 1). The watershed has a continental monsoon climate with a mean annual precipitation of $437 \mathrm{~mm}, 70 \%$ of which falls between June and September. The mean annual air temperature is $8.4^{\circ} \mathrm{C}$, and the accumulated temperature above $10^{\circ} \mathrm{C}$ is $3200^{\circ} \mathrm{C}$. The aridity index is 1.8 , and the mean annual wind speed is $2.2 \mathrm{~m} / \mathrm{s}$. The dominant soil types are Calcaric Regosols, Eutric Regosols, Calcaric Arenosols, and Calcaric Fluvisols (FAO/UNESCO, 1988) (Wang et al., 2009a).

The study area is in the center of a region of the CLP that is susceptible to severe soil erosion by both wind and water, which causes the eco-environment of the area to be fragile. The Chinese government has launched many ecological engineering projects since the 1980s (e.g., the "Grain for Green" project) to control soil erosion and improve the ecological environment in this area. These projects have significantly increased the area of land revegetated with perennial species (Chen et al., 2007; Lu et al., 2012). The watershed has three land use types that cover more than $86 \%$ of the total area: farmland (16\%), grassland (44\%), and shrubland (26\%, that includes a small proportion of forest). The remaining area is covered by wasteland, gully channels, and manmade structures. The grassland can be further classified as natural (dominated by Stipa bungeana) or planted (alfalfa) grassland. The watershed has been described in detail elsewhere (Gao and Shao, 2012; Jia et al., 2013; Jiang et al., 2013; She et al., 2010).

\subsection{Soil sampling and data collection}

We selected four typical land use types including farmland (soybean; Glycine max), natural grassland (S. bungeana), planted grassland (alfalfa; Medicago sativa), and shrubland (Caragana korshinskii) in order to monitor SWC under different land use types in the watershed. All of the land use sites were located at the crests of slopes with elevations ranging from 1205 to $1260 \mathrm{~m}$ (Table 1). At the central position of each land use site, disturbed soil samples were collected for the determination of soil organic carbon (SOC) content and fresh plant root indices. The samples were collected using a soil auger $(10 \mathrm{~cm}$ in diameter) to a depth of $21 \mathrm{~m}$. Samples were taken at $10-\mathrm{cm}$ intervals for the $0-0.2 \mathrm{~m}$ layer, $20-\mathrm{cm}$ intervals for the $0.2-6 \mathrm{~m}$ layer, and $50-\mathrm{cm}$ intervals for the 6-21 m layer. Therefore, a total of 55 samples were collected from each land use site to determine SOC and the plant root indices. The sampled depth of $21 \mathrm{~m}$ was based on the maximum root depth (18 m) observed across the CLP (Wang et al., 2013).

The SOC content was determined using the dichromate oxidation method (Nelson and Sommers, 1982). Live-root samples were carefully washed to remove all of the attached soil and were then allowed to dry for a short time on absorbent paper before being scanned on an Epson flatbed scanner. Root length was determined with a WinRHIZO $2009^{\circledR}$ (Regent Instruments, Montreal, QC, Canada) image analysis system.

After we collected the soil and plant root samples from each site, an aluminum neutron-probe access tube $(21 \mathrm{~m}$ in length, comprising three $6-\mathrm{m}$ tubes and one $3-\mathrm{m}$ tube connected in series) was installed at each land use site. The installations were allowed to stabilize for one month, and then slow-neutron counting rates (CRs) were obtained on 15 sampling dates between 30 September 2011 and 30 October 2013. The CRs were monitored at intervals of 10 and $20 \mathrm{~cm}$ for the $0-1 \mathrm{~m}$ and $1-21 \mathrm{~m}$ layers, respectively.

Gravimetric SWCs $\left(\theta, \mathrm{g} \mathrm{H}_{2} \mathrm{O} / 100 \mathrm{~g}\right.$ dry soil,\%) and bulk densities (BD, $\mathrm{g} / \mathrm{cm}^{3}$ dry soil) were also measured at eight locations (two near each of the four access tubes) during the monitoring period for calibrating the neutron probes. The direct measurement of BD within the $21-\mathrm{m}$ profiles presents a practical challenge. Therefore, only two 1-m deep pits were excavated under each land use type for collecting undisturbed soil samples at $10-\mathrm{cm}$ intervals. We measured $\theta$ with BD on only one occasion at each of the eight sites. Thus, 20 samples were collected from each land use type and the 80 samples in all provided the $\theta$ and BD data used for calibration. The ranges of $\theta$ and BD were from $1.6 \%$ to $19.6 \%$, and from 1.20 to $1.75 \mathrm{~g} / \mathrm{cm}^{3}$ respectively, which generally covered the range of $\theta$ and BD commonly observed in the study area and, therefore, would be representative when developing the calibration equation. According to a study in the same area (Hu et al., 2009), site-specific calibration curves from different sites in this area were almost the same (Hu et al., 2009). Therefore, one single linear calibration curve derived by pooling all of the CR data from different sites together produced comparable spatial means and standard deviations of SWC as the site-specific calibration curves did. Values of $\theta$ were transformed to corresponding volumetric SWCs (SWC, $\mathrm{cm}^{3} / \mathrm{cm}^{3}$ ). The SWCs were also calculated from the CRs determined by the neutron probes using the calibration curve:

$\mathrm{SWC}=62.233 \mathrm{CR}+0.9459\left(R^{2}=0.9239, P<0.001\right)$

The calculated SWCs were used to directly determine the vertical distributions and dynamics within the 21-m profiles.

Note that SWC was monitored within only one $21-\mathrm{m}$ profile for each land use type, due to the high cost of measurements. Nevertheless, the measured SWC in one-profile was considered to be representative of the soil-water regime of the land use type. This was because landscape, terrain, and climate conditions were relatively homogeneous among our sampling locations, which greatly reduced their effects on the vertical distributions of SWC.

To better evaluate the impact of land use on soil water, we further calculated the value of AWC for each site, considering that (i) the AWC was more sensitive to land use type than was SWC, and (ii) the use of AWC, to some extent, might weaken the impact of soil texture on soil water by excluding the water held below the permanent wilting point (PWP), although soil texture could still theoretically influence AWC. The AWC is given by. 


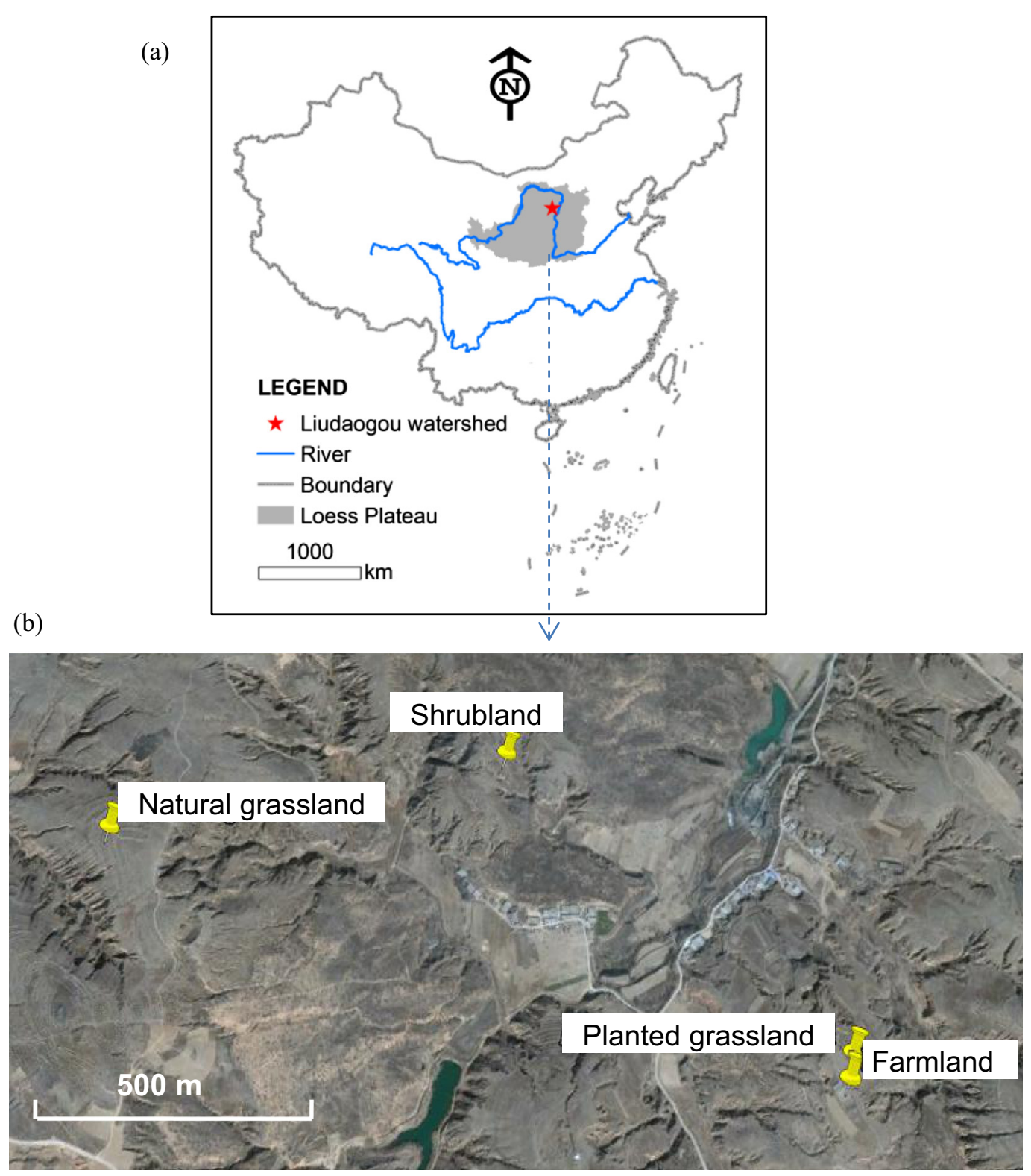

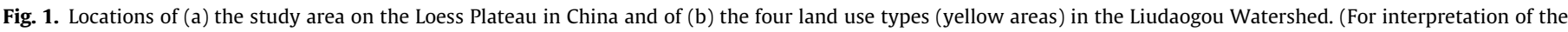
references to color in this figure legend, the reader is referred to the web version of this article.)

$\mathrm{AWC}=\mathrm{SWC}-\mathrm{PWP}$

The PWP was obtained by using a robust pedotransfer function, which has been described in detail by Wang et al. (2013).

The mean $\mathrm{AWS}_{1 \mathrm{~m}}$ in 0-1 m, 1-2 m, .., 20-21 m layers, was calculated as follows:

$\mathrm{AWS}_{1 \mathrm{~m}}=\sum_{d=0}^{100} \mathrm{AWC} \times \Delta d \times \mathrm{UFC}$

where $\Delta d$ is the thickness of the soil layer ( $\mathrm{cm} ;=100$ in this study); and $U F C$ is a unit conversion factor $\left(10 \mathrm{~mm} \mathrm{~cm}^{-1}\right)$. The value of $\mathrm{AWS}_{1 \mathrm{~m}}$ can directly indicate how much water is available for root uptake or that has been already absorbed by the plants. Therefore, in the current study we first evaluated the impact of land use type on the distributions and dynamics of SWC and AWC (Sections 3.1 and 3.2), and then assessed the time stability of $\mathrm{AWS}_{1 \mathrm{~m}}$ in the 21-m profile under different land use types (Sections 3.3 and 3.4).
2.3. Temporal stability analysis and mean $A W S_{1 m}$ estimation using the MTSD

The SWC datasets can represent well the different soil water conditions in different seasons because they were measured every one or two months. According to previous studies (Hu et al., 2012; Martínez-Fernández and Ceballos, 2003), SWC data from one year is enough to identify the MTSD, and the sampling frequency had little effect on the results (Guber et al., 2008). As such, we divided the $15 \mathrm{AWS}_{1 \mathrm{~m}}$ datasets into two groups: a calibration group comprising 9 datasets obtained between September 2011 and October 2012, and a validation group comprising 6 datasets obtained between December 2012 and October 2013. The calibration group was used to identify the MTSD. The validation group was used to test the possibility of using $\mathrm{AWS}_{1 \mathrm{~m}}$ measurements at the MTSD to estimate the mean AWS ${ }_{1 \mathrm{~m}}$ of a soil profile. Many temporal stability indices can be used to identify the MTSD used for 
Table 1

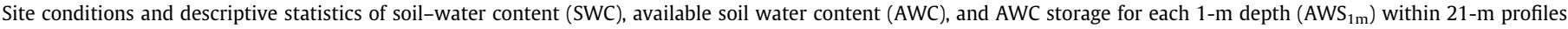
under the four land use types, measured on 15 occasions between 30 September 2011 and 30 October 2013. The number of measured SWCs was 1650.

\begin{tabular}{|c|c|c|c|c|c|c|c|}
\hline Land use & Vegetation, elevation & Soil water parameter & Min & Max & Mean & SD & $\mathrm{CV}(\%)$ \\
\hline \multirow[t]{3}{*}{ Farmland } & \multirow[t]{3}{*}{ Soybeans, $1220 \mathrm{~m}$} & SWC (\%) & 4.6 & 25.7 & 12.0 & 5.2 & 43 \\
\hline & & AWC (\%) & 2.2 & 16.6 & 7.1 & 2.8 & 39 \\
\hline & & $\mathrm{AWS}_{1 \mathrm{~m}}(\mathrm{~mm})$ & 44.6 & 126.9 & 71.4 & 24.3 & 34 \\
\hline \multirow[t]{3}{*}{ Natural grassland } & \multirow[t]{3}{*}{ Stipa bungeana, $1260 \mathrm{~m}$} & SWC & 6.8 & 22.1 & 14.8 & 3.0 & 20 \\
\hline & & AWC & 2.2 & 11.9 & 6.5 & 1.7 & 27 \\
\hline & & $\mathrm{AWS}_{1 \mathrm{~m}}$ & 32.8 & 87.1 & 65.3 & 12.3 & 19 \\
\hline \multirow[t]{3}{*}{ Planted grassland } & \multirow[t]{3}{*}{ Alfalfa, $1229 \mathrm{~m}$} & SWC & 3.6 & 26.2 & 10.0 & 4.4 & 44 \\
\hline & & AWC & 1.2 & 15.3 & 5.7 & 3.1 & 55 \\
\hline & & $\mathrm{AWS}_{1 \mathrm{~m}}$ & 23.3 & 138.0 & 57.7 & 30.2 & 52 \\
\hline \multirow[t]{3}{*}{ Shrubland } & \multirow[t]{3}{*}{ Caragana korshinskii, $1205 \mathrm{~m}$} & SWC & 3.3 & 23.9 & 9.7 & 3.3 & 34 \\
\hline & & AWC & 0.6 & 13.9 & 4.9 & 2.6 & 52 \\
\hline & & $\mathrm{AWS}_{1 \mathrm{~m}}$ & 13.0 & 114.1 & 50.3 & 24.9 & 50 \\
\hline
\end{tabular}

Notes: SD, standard deviation; CV, coefficient of variation.

estimating the mean $\mathrm{AWS}_{1 \mathrm{~m}}$ (Hu et al., 2012). By comparing the results of different indices, the mean absolute bias error (MABE) was determined to be the best (Hu et al., 2010a, 2010b). Therefore, the MTSD was identified at the depth with the lowest MABE values under each land use type. Using the $\mathrm{AWS}_{1 \mathrm{~m}}$ measurements at the determined MTSD, the mean $\mathrm{AWS}_{1 \mathrm{~m}}$ of a soil profile on different dates were estimated by considering the mean relative difference (MRD) between the AWS $1 \mathrm{~m}$ measurements at the MTSD and the mean $\mathrm{AWS}_{1 \mathrm{~m}}$ (Grayson and Western, 1998). A similar analysis was made for different sub-profiles $(0-3,0-4, \ldots, 0-21 \mathrm{~m})$ within the $21-\mathrm{m}$ profiles that determined whether the identified MTSD could be used to accurately estimate the mean $A_{W S_{1 m}}$ of soil profiles having different depths.

Root mean square deviation (RMSD) and absolute bias relative to the mean (RBIAS) (Brocca et al., 2009, 2012; Hu et al., 2010b; $\mathrm{Hu}$ and $\mathrm{Si}, 2014$ ), were used to evaluate the accuracy of the mean AWS $_{1 \mathrm{~m}}$ estimations in the different sub-profiles. The RMSD and RBIAS could be used to infer the absolute difference and relative difference between the measured and estimated $A W S_{1 \mathrm{~m}}$, respectively. The best mean $\mathrm{AWS}_{1 \mathrm{~m}}$ estimation would correspond to the minimum RMSD and RBIAS values. Usually, a prediction with RBIAS less than 0.05 or 0.1 is acceptable in the hydrology community (Hu and Si, 2014; Peterson and Wicks, 2006).

\subsection{Data analysis}

Basic statistics including the mean, standard deviation, and coefficient of variation (CV) for the SWC and/or AWC data under the four land use types were calculated using Microsoft Excel (version 2010). Temporal stability and the estimation of mean $A_{W} S_{1 \mathrm{~m}}$ with the MTSD were analyzed using the MATLAB code tsa.m (Hu et al., 2012), which is available online at https://www.researchgate.net/profile/Wei_Hu4/contributions?eV=prf_act.

\section{Results and discussion}

\subsection{Basic statistics of soil water within the 21-m profiles}

\subsubsection{Soil-water content}

The measured SWCs of the 21-m profiles in the depth-time domain varied during the 2011-2013 study period from $4.6 \%$ to $25.7 \%$ for farmland, $6.8-22.1 \%$ for natural grassland, $3.6-26.2 \%$ for planted grassland, and 3.3-23.9\% for shrubland (Table 1 ). The variability of the SWCs within the profiles under each land use type may be due mainly to the combined effects of the vertical heterogeneities of soil texture and plant-root density (Wang et al., 2013).
In addition, the possible preferential flow paths created by root decay or by the vertical joints found in loessial soils may also partly explain the vertical variability in SWC (Wang et al., 2009b). The dynamics of plant growth and the seasonal variability of meteorological conditions would contribute to temporal changes in SWC (Fan et al., 2010; Hu et al., 2010a). Note that the soil in the profiles could never be saturated during the rainy seasons due to the relatively coarse texture of the loessial soils and the very deep groundwater table (i.e., often below $60 \mathrm{~m}$ ) on the hillslopes on which our measurements were obtained.

Of the four land use types, natural grassland had the highest mean SWC (14.8\%) in the 21 -m soil profile, followed by those of farmland and planted grassland (Fig. 3A). The mean SWC was lowest (9.7\%) under shrubland. These differences between the mean SWCs under the four land use types were statistically significant $(P<0.05)$, except between those under planted grassland and shrubland, indicating the large effect of land use on soil-water conditions to a depth of $21 \mathrm{~m}$. The CVs in the space domain ranged from $20 \%$ under natural grassland to $44 \%$ under planted grassland, implying that land use affected not only the SWCs, but also the magnitudes of the spatial variation of SWC. The land use effects were also evident in the variations of SOC content and plant root length observed among the different land use types (Fig. 2). In the root zone, SWC was strongly correlated with root mass in the deep profile (Wang et al., 2013).

\subsubsection{Available soil-water content}

Table 1 lists the basic statistics of the measured AWCs within the 21-m profiles in the depth-time domain during the 20112013 study periods. The AWC varied from $2.2 \%$ to $16.6 \%, 2.2 \%$ to $11.9 \%, 1.2 \%$ to $15.3 \%$, and $0.6 \%$ to $13.9 \%$ under farmland, natural grassland, planted grassland, and shrubland, respectively (Table 1). The lowest value of AWC was found under shrubland, indicating that shrubland had led to the largest decreasing of AWC in our study area. Consequently, such an extensive extraction of soil water had caused the occurrence of dried soil layers (DSLs) in the profile (Wang et al., 2010). The DSLs were also found under the planted grassland and natural grassland, but those DSLs were thinner than that under shrubland.

Fig. 3B shows that the differences in mean AWCs in the depth-time domain under the four land use types were significant $(P<0.05)$ and followed the order: farmland $(7.1 \%)>$ natural grassland $(6.5 \%)>$ planted grassland $(5.7 \%)>$ shrubland $(4.9 \%)$. As expected, such a difference in soil water was in accordance with the results of previous studies conducted in the same area (Wang et al., 2010). The significant difference $(P<0.05)$ of AWC between planted grassland and shrubland differed from that of SWC 


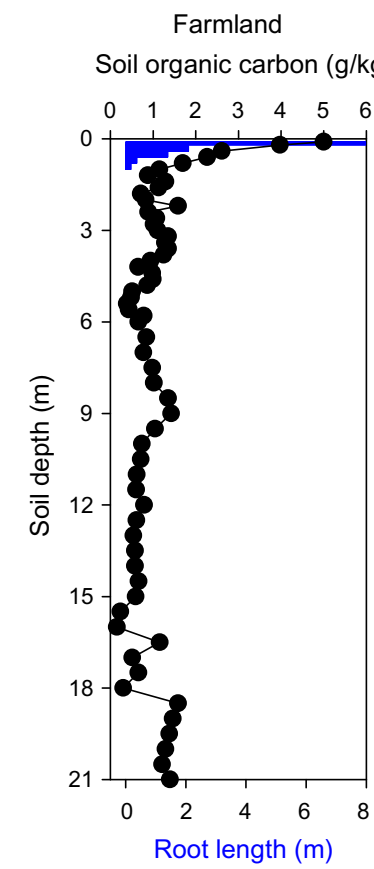

Natural grassland

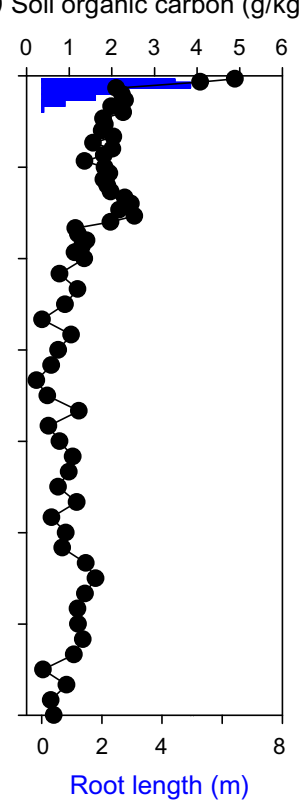

Planted grassland

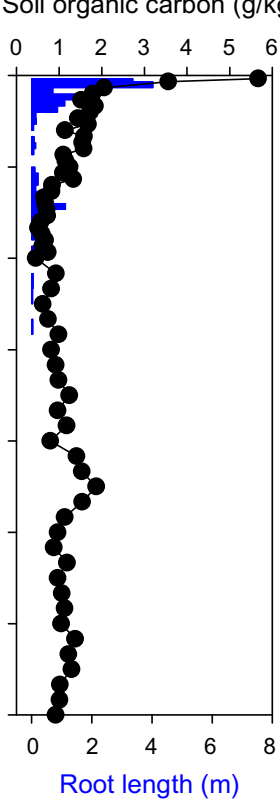

Shrubland

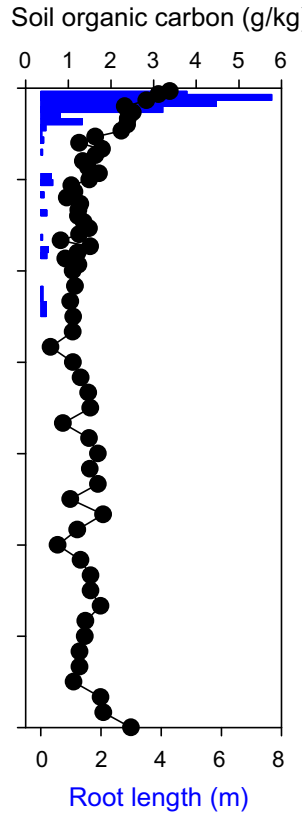

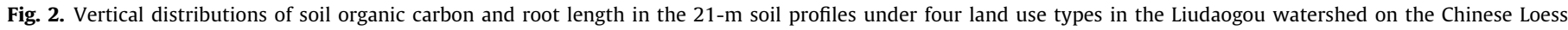

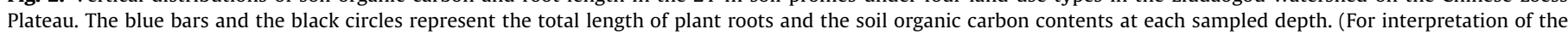
references to colour in this figure legend, the reader is referred to the web version of this article.)
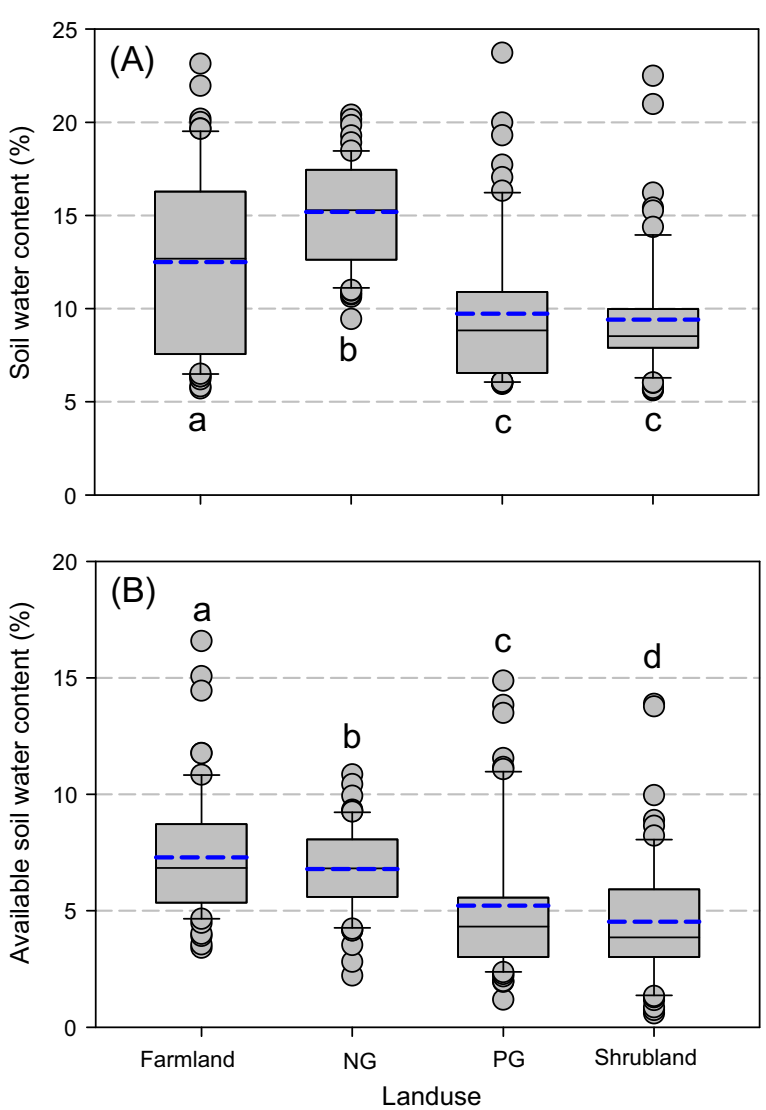

Fig. 3. Boxplots of (A) soil water content and (B) available soil water content within the 21-m soil profiles for farmland, natural grassland (NG), planted grassland (PG), and shrubland. Different lowercase letters indicate significant differences in soil water among the land use types (LSD, $P<0.05$ ).
$(P>0.05)$, implying that AWC was more sensitive to land use type than SWC was.

For each land use type, with the exception of farmland, the CV of AWC in the space domain was greater than that of SWC (Table 1). This indicated that there were stronger variations in AWC. These were attributed to the differences in the amounts and distributions of plant roots in the soil profile as well as to the different root-water-uptake characteristics among the different vegetation types (Fig. 2).

\subsection{Dynamics of soil-water under different land use types}

\subsubsection{Soil-water content}

The vertical distributions of SWC in the 21-m profiles differed greatly among the four land use types (Fig. 4), but were similar over time, especially for soil layers below $2 \mathrm{~m}$. The CVs of the SWCs in the time domain for each sampled soil layer identified two distinct layers in which the dynamic changes in SWC occurred differently within the 21-m profile: i.e., an active layer (0-2 m; CVs generally $>10 \%$ ) and a relatively stable layer (2-21 m; CVs generally $<10 \%$ ).

The changes in the SWC regime in the active layer were caused by rainwater infiltration, water redistribution, and evapotranspiration (Wang et al., 2012; Western et al., 2002; Yang et al., 2012). However, changes in the water regime of the relatively stable layer might have been due to the uptake of water by deep roots, preferential flow of soil water, and soil properties associated with water retention (Markewitz et al., 2010; Wang et al., 2013). Fig. 5 further illustrates that the SWCs in the active layer were seasonally variable, but that the SWCs in the stable layer were more consistent over time. This is in agreement with the enhanced temporal stability of soil-water storage that occurs with increasing soil depth from 1 to $3 \mathrm{~m}$ (Gao and Shao (2012). Due to the deep groundwater table (i.e., often $60 \mathrm{~m}$ below the soil surface), changes in groundwater could have no effect on SWC in the stable layer. 

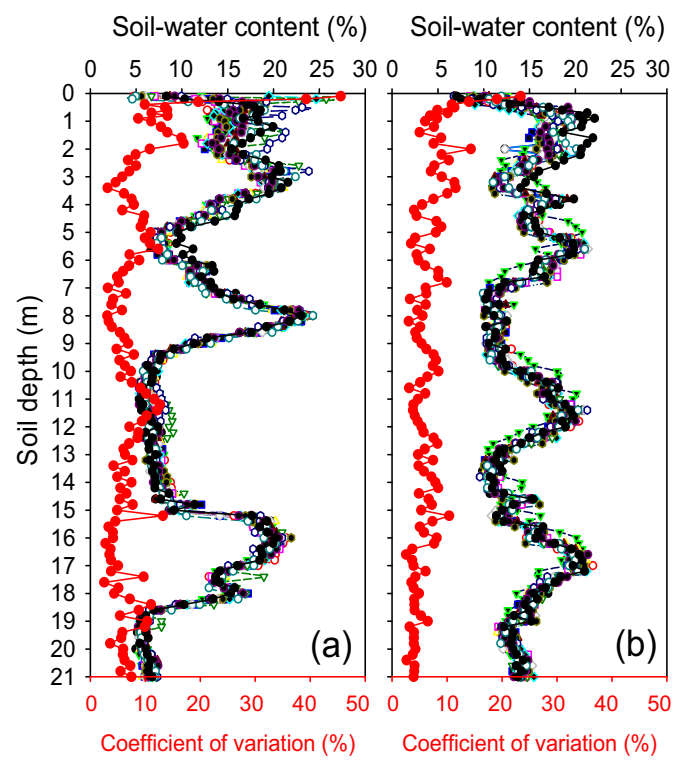

Soil-water content (\%)

Soil-water content (\%)
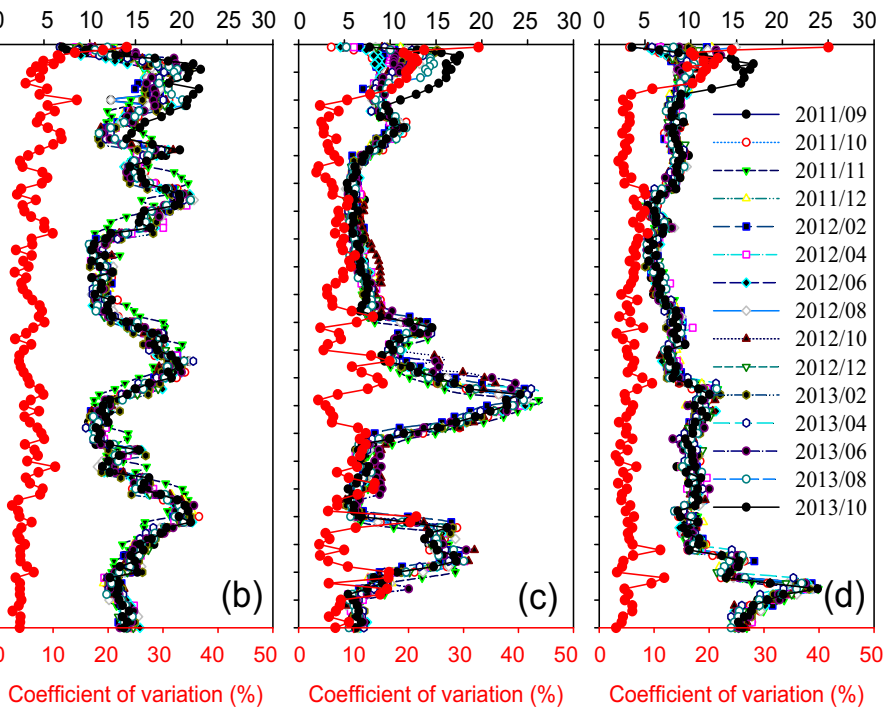

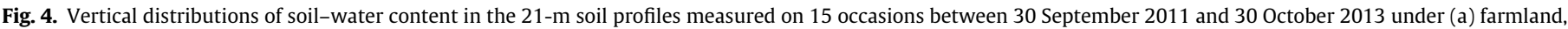

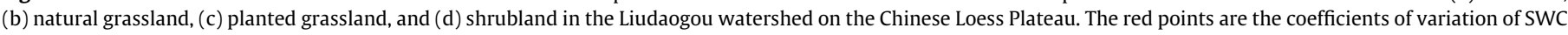

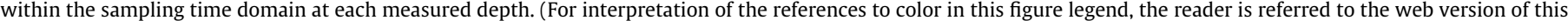
article.)

\subsubsection{Available soil-water}

Among the four land use types, the $\mathrm{AWS}_{1 \mathrm{~m}}$ in the $21-\mathrm{m}$ profiles, in the time domain, ranged from 44.6 to $126.9 \mathrm{~mm}, 32.8$ to $87.1 \mathrm{~mm}, 23.3$ to $138.0 \mathrm{~mm}$, and 13.0 to $114.1 \mathrm{~mm}$ for farmland, natural grassland, planted grassland, and shrubland, respectively (Table 1). As with the AWC data (Fig. 3B), the mean $\mathrm{AWS}_{1 \mathrm{~m}}$ (Table 1$)(P<0.05)$ and the total storage of available soil water in the 21-m-profile (Fig. 6) $(P<0.001)$ followed the order: farmland $>$ natural grassland $>$ planted grassland $>$ shrubland.

It might be expected that the vertical distribution patterns of the mean AWCs in the 21-m profile should differ from those of the mean SWCs in the time domain under each of the four land use types. This might occur because the effects of the vertical heterogeneity of soil texture on AWC would be reduced, to a certain extent, by excluding the water held below the PWP (Bormann, 2012; Markewitz et al., 2010). The CVs of $\mathrm{AWS}_{1 \mathrm{~m}}$ in the time domain under farmland, natural grassland, planted grassland, and shrubland, were $9.0 \%, 9.2 \%, 13.4 \%$, and $8.0 \%$, respectively, which were correspondingly higher than those of SWC $(8.1 \%, 6.5 \%$, $10.0 \%$, and $7.3 \%$, respectively), indicating greater temporal variation in AWC than in SWC. This was mainly attributed to the seasonal-change characteristics of root water uptake and to rainfall, infiltration and redistribution processes. Liu et al. (2012) observed strong relationships among AWCs and reflectance and vegetation indices in a grassland ecosystem in California during the growing season, and the wet and the dry seasons; while, the use of AWC further improved the relationships by reducing soil property effects. Breshears et al. (2009) found that the frequency of AWC varied significantly with precipitation amount and type, both vertically with soil depth and horizontally with vegetation type; they further pointed out that the spatiotemporal variation of AWC was substantial and needed to be explicitly considered when predicting vegetation responses to land use type and climate change in water-limited ecosystems.

Hereafter, we used the AWS $1 \mathrm{~m}$ as an index of soil water to conduct time stability analyses in the $21-\mathrm{m}$ profiles to evaluate better the influence of land use type on the temporal stability of soil water within deep profiles.

\subsection{Temporal stability of $A W S_{1 m}$}

\subsubsection{General characteristics of the temporal stability of $A W S_{1 m}$ in the} 0-21 $\mathrm{m}$ profiles

The MRDs and the associated temporal-stability index MABE are presented for each soil layer in the $21-\mathrm{m}$ profile in Fig. 7. The ranges of the MRDs in farmland, natural grassland, planted grassland, and shrubland were $118.1 \%$ ( $-37.3 \%$ to $80.9 \%$ ), $75.1 \%$ ( $-47.6 \%$ to $27.5 \%), 196.4 \%$ ( $-58.9 \%$ to $137.5 \%$ ), and $200.6 \%$ ( $-72.6 \%$ to $128.0 \%$ ), respectively. Shrubland had the widest MRD range while natural grassland had the narrowest range. These ranges of MRDs in the vertical direction were generally lower than the ranges in the horizontal direction reported by Grayson and Western (1998), Mohanty and Skaggs (2001), and Hu et al. (2010a). This was because only local controlling factors tended to play a role in determining soil water in the vertical direction. Thus, variations in soil water in the vertical direction were not affected by non-local controlling factors, such as topography, during a rainfall event.

The MABEs were generally low for all land use types, which indicated that the $\mathrm{ASW}_{1 \mathrm{~m}}$ were temporally stable (Fig. 7). If a MABE value of $10 \%$ was defined as the critical value, then most $\mathrm{ASW}_{1 \mathrm{~m}}$ depths were time stable except for two under farmland (0-1 $\mathrm{m}$ and 1-2 $\mathrm{m})$, two under natural grassland $(0-1 \mathrm{~m}$ and 6-7 m), five under planted grassland $(0-1 \mathrm{~m}, 3-4 \mathrm{~m}, 11-12 \mathrm{~m}$, 13-14 $\mathrm{m}$, and $14-15 \mathrm{~m})$, and one under shrubland $(0-1 \mathrm{~m})$. The ranges of MABEs among the four land use types were $1.8-28.4 \%$, which were generally lower than the reported ranges in the horizontal direction in the same study area (Hu et al., 2010a; Hu and Si, 2014); however, the weakest time stability for soil water was found in the surface $(0-1 \mathrm{~m})$ depth in the $21-\mathrm{m}$ profile as indicated by the largest MABE in Fig. 7, which was also in agreement with their findings.

The identified MTSDs varied with land use, and were at depths of $18,15,9$, and $16 \mathrm{~m}$ under farmland, natural grassland, planted grassland, and shrubland, respectively (Table 2). The different land use types were expected to induce different MTSDs because the 

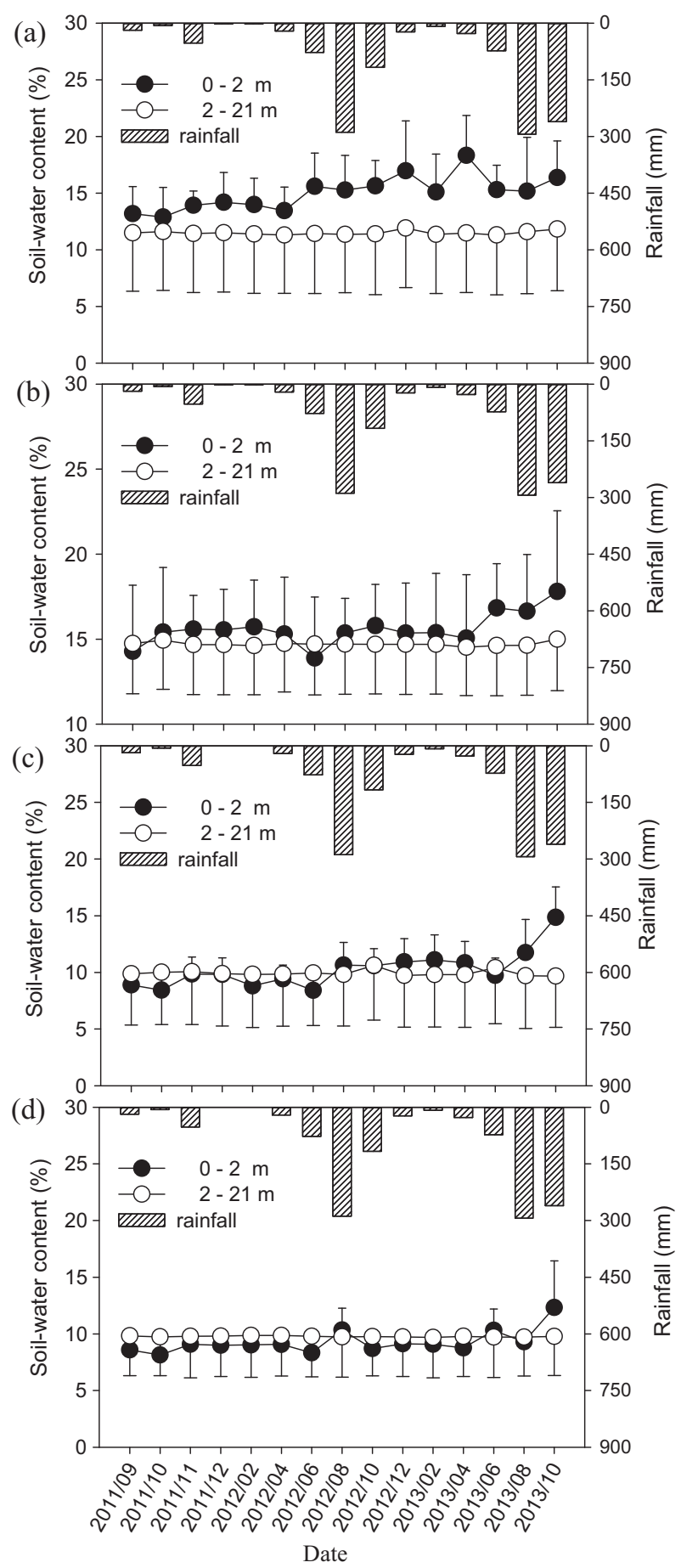

Fig. 5. Soil-water contents over time in the $0-2 \mathrm{~m}$ and $2-21 \mathrm{~m}$ layers under (a) farmland, (b) natural grassland, (c) planted grassland, and (d) shrubland, in the Liudaogou watershed on the Chinese Loess Plateau. Error bars represent the standard deviations of the means.

processes affecting soil water depended greatly on the type, coverage, and root distribution of the vegetation comprising a given land use type (Williams et al., 2003; Yang et al., 2012; Zucco et al., 2014). Hydrological (e.g., interception of rain by vegetation, surface runoff, infiltration, and redistribution) and ecological (e.g., sap flow, root water uptake, and hydraulic redistribution) processes under different land use types could lead to different soil-water regimes (Abdelkadir and Yimer, 2011; Lee et al., 2005; Nosetto et al., 2005) and could consequently affect the temporal stability

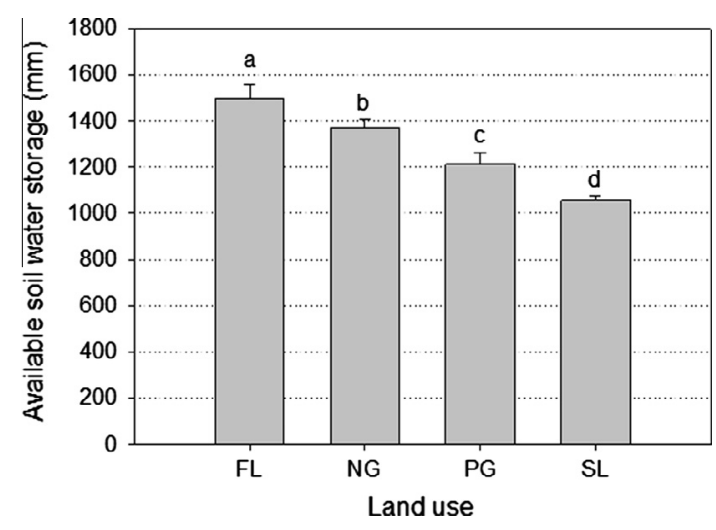

Fig. 6. The total storage of available water (AWS) in the 21-m profiles under farmland (FL), natural grassland (NG), planted grassland (PG), and shrubland (SL). Different letters indicate significant differences of AWS among land use types (LSD, $P<0.001)$.

of $\mathrm{ASW}_{1 \mathrm{~m}}$. Therefore, our results verified the hypothesis that the temporal stability of $\mathrm{ASW}_{1 \mathrm{~m}}$ in the vertical direction is affected by land use. The accuracy of the mean ASW $_{1 \mathrm{~m}}$ estimation also differed with land use type, and the best accuracy was observed under shrubland for both the calibration and validation groups of datasets, with RMSD values of 1.4 and $1.9 \mathrm{~mm}$, and RBIAS values of 0.02 and 0.03 , respectively (Table 2 ).

\subsubsection{Changes in the MTSDs within soil sub-profiles}

Fig. 8 shows the MTSDs identified for estimating mean ASW $_{1 \mathrm{~m}}$ in the $0-3,0-4, \ldots, 0-21 \mathrm{~m}$ soil sub-profiles. The MABE values generally decreased with increasing soil sub-profile thickness. The MTSDs for each sub-profile identified by the MABE varied greatly under natural grassland but were relatively similar under the other three land use types.

The MTSDs generally increased in a step-like manner under the four land use types, were most obvious under farmland as the soil sub-profile thickness increased from $0-3 \mathrm{~m}$ to $0-21 \mathrm{~m}$, and were land use dependent (Fig. 8). The range of MTSDs were $3-18 \mathrm{~m}$, 2-15 $\mathrm{m}, 2-9 \mathrm{~m}$, and 3-20 $\mathrm{m}$, under the farmland, natural grassland, planted grassland, and shrubland, respectively, indicating that a wider range of MTSDs and deeper MTSDs for deeper soil profiles occurred under different land use types. The mean ASW $_{1 \mathrm{~m}}$ values were different under the four land use types (Table 1) and hence the MTSD depended on the soil-water processes in association with the soil-water conditions. The factors controlling soil water clearly differed between the dry (mainly air entry pressure, soil texture, and root water uptake capacity) and the wet (mainly hydraulic conductivity and soil porosity) sections of the soil, thereby leading to different temporal stabilities of $\mathrm{ASW}_{1 \mathrm{~m}}$ (Brocca et al., 2007; Penna et al., 2013; Rosenbaum et al., 2012).

\subsubsection{Estimating mean $A W S_{1 m}$ of the profiles under the different land} use types

The accuracy of the mean ASW $_{1 \mathrm{~m}}$ estimation was evaluated for each sub-profile using the validation group. The overall estimation was acceptable, with the means of the RMSD and RBIAS ranging from 3.6 to $7.7 \mathrm{~mm}$ and from 0.07 to 0.12 , respectively, for the four land use types (Table 3 ). However, the accuracy of the mean $\mathrm{ASW}_{1 \mathrm{~m}}$ estimation for the sub-profiles differed with the land use type. The best accuracy was obtained for the shrubland, as indicated by the lowest RMSD (1.2 and $3.6 \mathrm{~mm}$ ) and RBIAS (0.03 and 0.07 ) values in the calibration and validation groups, respectively, followed by those for natural grassland and farmland. The accuracy of the estimation was worst for the planted grassland, with the highest RMSD $(7.7 \mathrm{~mm})$ and RBIAS $(0.12 \mathrm{~mm})$ values in the validation group. 

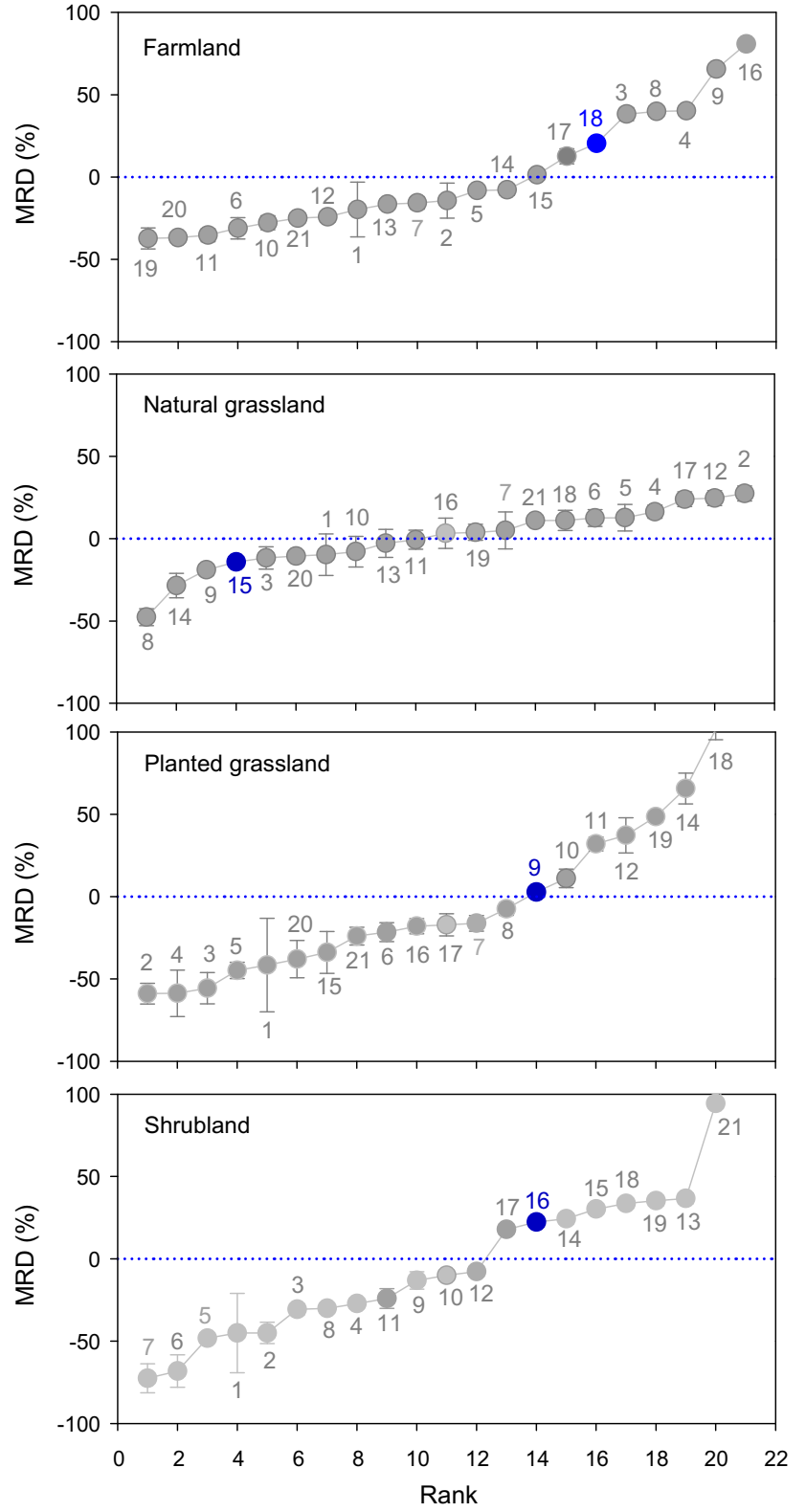

Fig. 7. Ranked (1-21) mean relative differences (MRD, indicated by gray circles) of available soil-water content for each $1-\mathrm{m}$ layer within the $21-\mathrm{m}$ soil profiles under four land uses types. Error bars represent the mean absolute bias error (MABE). The most temporally stable depth with the lowest MABE is marked by the blue circle. (For interpretation of the references to colour in this figure legend, the reader is referred to the web version of this article.)

Table 2

Performance of the MTSD identified by MABE in estimating the mean available soil water storage $(\mathrm{mm})$ at each $1-\mathrm{m}$ depth $\left(\mathrm{AWS}_{1 \mathrm{~m}}\right)$ within $21-\mathrm{m}$ soil profiles under four land use types. Two evaluation indices (RMSD and RBIAS) were used to evaluate the accuracy of the mean $\mathrm{AWS}_{1 \mathrm{~m}}$ estimation.

\begin{tabular}{|c|c|c|c|c|c|}
\hline \multirow[t]{2}{*}{ Land use } & \multirow[t]{2}{*}{$\operatorname{MTSD}(\mathrm{m})$} & \multicolumn{2}{|c|}{ Calibration dataset } & \multicolumn{2}{|c|}{ Validation dataset } \\
\hline & & RMSD (mm) & RBIAS & $\operatorname{RMSD}(\mathrm{mm})$ & RBIAS \\
\hline Farmland & 18 & 1.6 & 0.02 & 4.8 & 0.06 \\
\hline Natural grassland & 15 & 2.3 & 0.03 & 2.3 & 0.03 \\
\hline Planted grassland & 9 & 1.7 & 0.02 & 5.1 & 0.08 \\
\hline Shrubland & 16 & 1.4 & 0.02 & 1.9 & 0.03 \\
\hline
\end{tabular}

Notes: MTSD, most temporally stable depth; MABE, mean absolute bias error; RMSD, root mean square deviation; RBIAS, absolute bias relative to the mean.
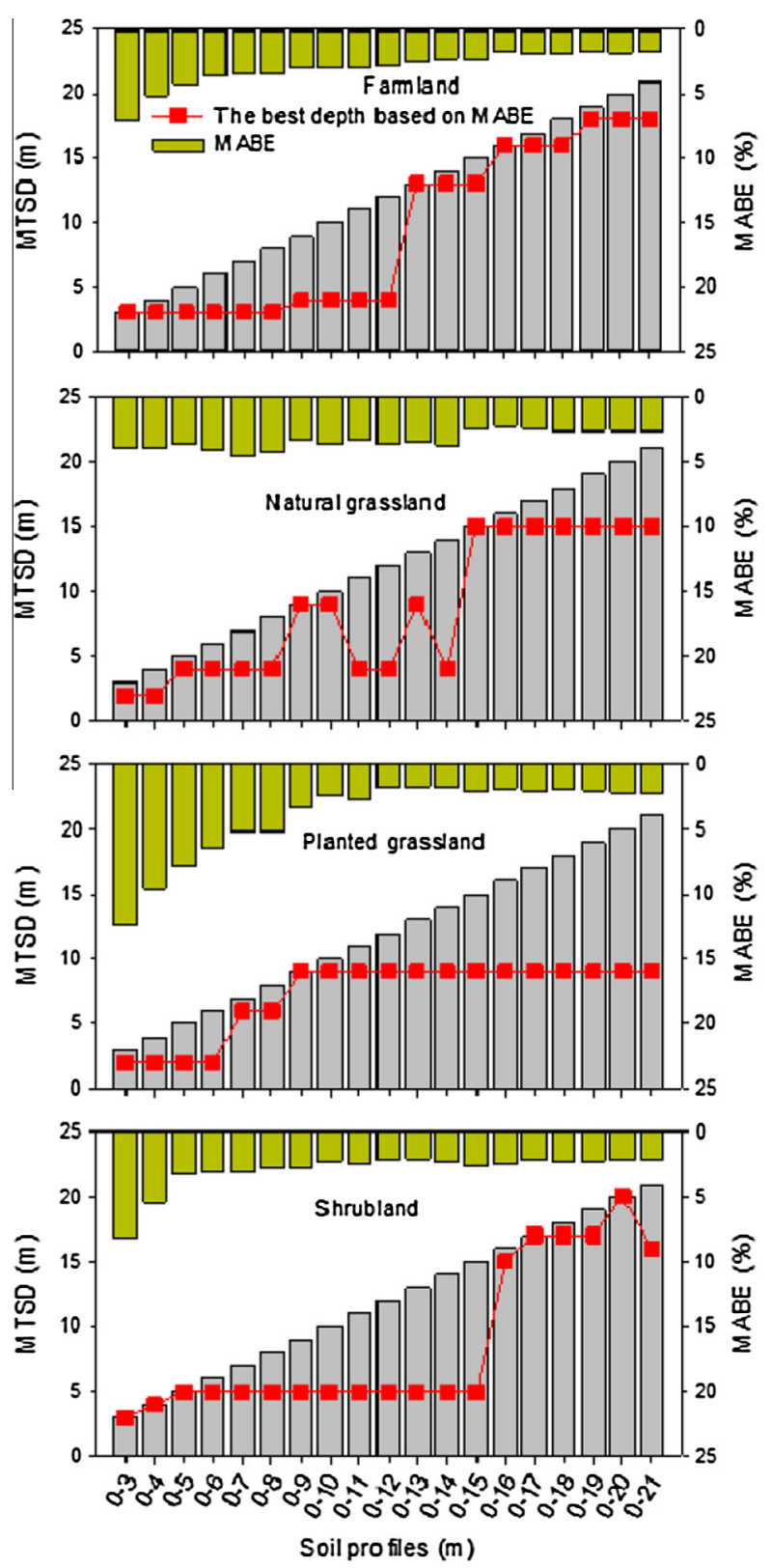

Fig. 8. The most temporally stable depth (MTSD) for measuring mean available soil-water storage at each 1 -m-depth in various soil sub-profiles $(0-3,0-4, \ldots$ 0-21 m) under (a) farmland, (b) natural grassland, (c) planted grassland, and (d) shrubland. Mean absolute bias errors (MABEs) for each sub-profile are also presented.

The RMSD and RBIAS for the four land use types tended to decrease in both the calibration and validation groups as the soil sub-profile thickness increased (Fig. 9), implying that the accuracy of the estimated MTSDs generally increased with increasing sub-profile thickness. This result is important because AWC data for deeper soil layers is more difficult to collect and having knowledge of an optimal sampling depth where the accuracy of the estimation is reasonable can lead to a more cost effective sampling strategy. The alternative emphasis is on the balance between benefits of increasing the accuracy and the disadvantages of increasing sampling efforts. These relationships could be due to the heterogeneities of the soil profiles (including soil properties and root characteristics) because clearly increases in the heterogeneity of the soils can adversely affect the estimation accuracy of the MTSD in temporal-stability theory. For example, the presence of 
Table 3

Overall performance of the MTSD determined using MABE in predicting mean available soil water storage at each $1-\mathrm{m}$ depth for the soil sub-profiles (0-3, 0$4, \ldots, 0-21 \mathrm{~m}$ ) under four land use types. Two evaluation indices (RMSD and RBIAS) were used to evaluate the accuracy of the predictions.

\begin{tabular}{|c|c|c|c|c|c|}
\hline \multirow[t]{2}{*}{ Land use } & \multirow[t]{2}{*}{ Statistic } & \multicolumn{2}{|c|}{ Calibration dataset } & \multicolumn{2}{|c|}{ Validation dataset } \\
\hline & & RMSD (mm) & RBIAS & RMSD (mm) & RBIAS \\
\hline \multirow[t]{2}{*}{ Farmland } & Mean & 2.5 & 0.03 & 7.0 & 0.07 \\
\hline & SD & 1.0 & 0.01 & 2.5 & 0.03 \\
\hline \multirow[t]{2}{*}{ Natural grassland } & Mean & 2.8 & 0.03 & 5.5 & 0.07 \\
\hline & SD & 0.7 & 0.01 & 2.6 & 0.04 \\
\hline \multirow[t]{2}{*}{ Planted grassland } & Mean & 1.8 & 0.04 & 7.7 & 0.12 \\
\hline & $\mathrm{SD}$ & 0.8 & 0.03 & 4.2 & 0.06 \\
\hline \multirow[t]{2}{*}{ Shrubland } & Mean & 1.3 & 0.03 & 3.6 & 0.07 \\
\hline & SD & 0.6 & 0.02 & 1.9 & 0.03 \\
\hline
\end{tabular}

Notes: MTSD, most temporally stable depth; MABE, mean absolute bias error; RMSD, root mean square deviation; RBIAS, absolute bias relative to the mean; SD, standard deviation.

a paleosol layer or an absence of root water uptake can significantly increase the SWC (Wu et al., 2011) and thus affect the temporal stability of soil water.

Some of the RMSD and RBIAS values in Fig. 9 indicated high variability, especially under farmland and planted grassland, which may also have been due to the heterogeneity of the soil properties and plant root distributions within the soil profiles (Fig. 2). The high SWCs in the deep soil profiles generally corresponded to the occurrence of the paleosol layers and a lower proportion of plant roots.

\subsection{Applications of the MTSD for measurements of deep soil water}

Our study investigated the characteristics of temporal stability of ASW $_{1 \mathrm{~m}}$ to a depth of $21 \mathrm{~m}$ and ascertained the MTSDs and their vertical changes for each sub-profile. We found that (1) the mean
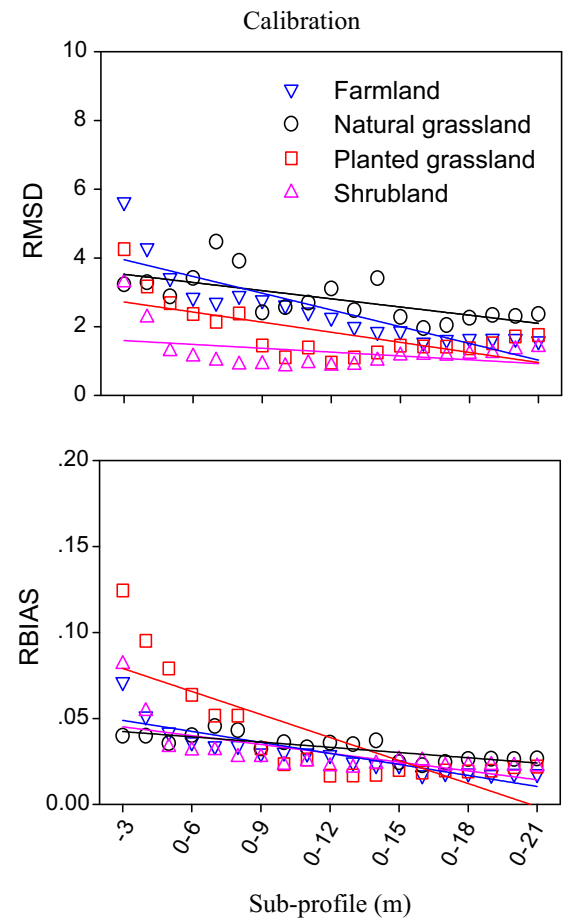

$\mathrm{ASW}_{1 \mathrm{~m}}$ for the different deep sub-profiles could be satisfactorily estimated by using the corresponding MTSDs, and (2) the MTSDs for each sub-profile were all shallower than $18 \mathrm{~m}$, with the exception of one depth under shrubland (Fig. 8), indicating that we could usually estimate the mean $\mathrm{ASW}_{1 \mathrm{~m}}$ in the $21-\mathrm{m}$ profile by measuring $\mathrm{ASW}_{1 \mathrm{~m}}$ at a maximum depth of $18 \mathrm{~m}$ combined with a temporal stability analysis. The depth of the $\mathrm{ASW}_{1 \mathrm{~m}}$ measurement may be $15 \mathrm{~m}$ or less for land uses such as the natural and planted grasslands. For the validation group, the values of RMSD and RBIAS (Fig. 9) further indicated that measurements at the MTSD could be used to predict the mean $\mathrm{ASW}_{1 \mathrm{~m}}$ of the soil profile in the vertical direction due to the existence of temporal stability.

The analysis of temporal stability in the vertical direction has rarely been reported due to the limited soil water data for deep soils, and where the dynamics of the soil water have been never been measured to a depth of $21 \mathrm{~m}$, as they were in the present study. The SWC below $21 \mathrm{~m}$ (i.e., at $22.4 \mathrm{~m}$ ) has been previously measured only once (Wang et al., 2009b), but information about the dynamics of deep soil water were not available. Land use greatly affected the vertical distribution patterns and temporal stabilities of $\mathrm{ASW}_{1 \mathrm{~m}}$ in deep soils. Our results will be of relevance in the fields of soil science, hydrology, and ecology for determining the MTSD for use in ASW Im $_{1 \mathrm{~m}}$ estimation, which will save labor, time, and money required for measurements below the MTSD.

\section{Conclusions}

The vertical distribution patterns and temporal stabilities of soil water to a depth of $21 \mathrm{~m}$ under four typical land use types on the CLP were investigated. The measured SWC was highly variable with depth and time under all land use types. The dynamic changes in SWC occurring within the $21-\mathrm{m}$ profiles could be partitioned between an active layer $(0-2 \mathrm{~m})$ and a stable layer $(2-21 \mathrm{~m})$ and were controlled by different ecological and hydrological processes occurring in the corresponding soil layers. The AWCs among the four land use types in the depth-time domain differed significantly
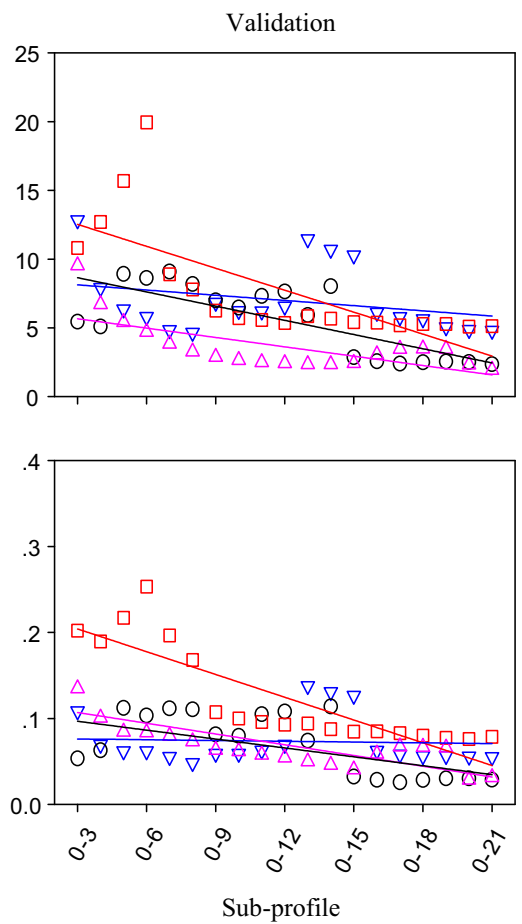

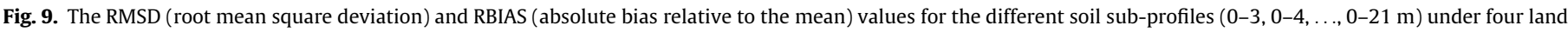
use types for the calibration and validation datasets. 
$(P<0.05)$, and followed the order: farmland $>$ natural grassland $>$ planted grassland $>$ shrubland. The mean $\mathrm{AWS}_{1 \mathrm{~m}}$ in the $21-\mathrm{m}$ profiles, in the time domain, ranged from 50.3 to $71.4 \mathrm{~mm}$ among the four land use types.

The ASW ${ }_{1 \mathrm{~m}}$ was temporally stable in the $21-\mathrm{m}$ soil profiles. The depth of the MTSDs under the four land use types tended to increase step-like as the soil sub-profile thickness increased from $0-3 \mathrm{~m}$ to $0-21 \mathrm{~m}$. The accuracy of the mean $\mathrm{ASW}_{1 \mathrm{~m}}$ estimation obtained by using the MTSDs was generally acceptable for all of the sub-profiles. Therefore, the mean $\mathrm{ASW}_{1 \mathrm{~m}}$ in the $21-\mathrm{m}$ profiles could be satisfactorily estimated by measuring soil water at a shallower depth (i.e., the MTSD) than $21 \mathrm{~m}$, in combination with temporal stability analysis, which would save labor, time, and money spent acquiring measured data below the MTSD. Vertical distribution patterns and the temporal stabilities of the soil water within the deep soils were highly dependent on the land use type.

\section{Acknowledgements}

This study was supported by the National Natural Science Foundation of China (Nos. 41101204, 41071156, and 41471189), the New Star Foundation on Shaanxi Province Youth Science and Technology (2013KJXX-09), and West Light Foundation of the Chinese Academy of Sciences. Special thanks also go to Dr. William Blackhall and Mr. David Warrington for their zealous help in improving the manuscript. The editor and anonymous reviewers are greatly appreciated for their constructive comments on our manuscript.

\section{References}

Albergel, C., Rudiger, C., Pellarin, T., Calvet, J.C., Fritz, N., Froissard, F., Suquia, D., Petitpa, A., Piguet, B., Martin, E., 2008. From near-surface to root-zone soil moisture using an exponential filter: an assessment of the method based on insitu observations and model simulations. Hydrol. Earth Syst. Sci. 12 (6), $1323-$ 1337.

Bormann, H., 2012. Assessing the soil texture-specific sensitivity of simulated soil moisture to projected climate change by SVAT modelling. Geoderma 185, $73-$ 83.

Breshears, D.D., Myers, O.B., Barnes, F.J., 2009. Horizontal heterogeneity in the frequency of plant-available water with woodland intercanopy-canopy vegetation patch type rivals that occurring vertically by soil depth. Ecohydrology 2 (4), 503-519.

Brocca, L., Morbidelli, R., Melone, F., Moramarco, T., 2007. Soil moisture spatial variability in experimental areas of central Italy. J. Hydrol. 333 (2-4), 356-373.

Brocca, L., Melone, F., Moramarco, T., Morbidelli, R., 2009. Soil moisture temporal stability over experimental areas in Central Italy. Geoderma 148 (3-4), 364374.

Brocca, L., Melone, F., Moramarco, T., Morbidelli, R., 2010. Spatial-temporal variability of soil moisture and its estimation across scales. Water Resour. Res. 46, 1-8.

Brocca, L., Tullo, T., Melone, F., Moramarco, T., Morbidelli, R., 2012. Catchment scale soil moisture spatial-temporal variability. J. Hydrol. 422, 63-75.

Brocca, L., Tarpanelli, A., Moramarco, T., Melone, F., Ratto, S.M., Cauduro, M., Ferraris, S., Berni, N., Ponziani, F., Wagner, W., Melzer, T., 2013. Soil moisture estimation in alpine catchments through modeling and satellite observations. Vadose Zone J. 12 (3).

Chaney, N.W., Roundy, J.K., Herrera-Estrada, J.E., Wood, E.F., 2015. High-resolution modeling of the spatial heterogeneity of soil moisture: applications in network design. Water Resour. Res. 51 (1), 619-638.

Chen, L.D., Wei, W., Fu, B.J., Lü, Y.H., 2007. Soil and water conservation on the Loess Plateau in China: review and perspective. Prog. Phys. Geogr. 31 (4), 389-403.

Corradini, C., 2014. Soil moisture in the development of hydrological processes and its determination at different spatial scales. J. Hydrol. 516, 1-5.

Corradini, C., Melone, F., Smith, R.E., 2000. Modeling local infiltration for a twolayered soil under complex rainfall patterns. J. Hydrol. 237 (1-2), 58-73.

Das, N.N., Mohanty, B.P., 2006. Root zone soil moisture assessment using remote sensing and vadose zone modeling. Vadose Zone J. 5 (1), 296-307.

Davidson, E., Lefebvre, P.A., Brando, P.M., Ray, D.M., Trumbore, S.E., Solorzano, L.A., Ferreira, J.N., Bustamante, M.M.D., Nepstad, D.C., 2011. Carbon inputs and water uptake in deep soils of an eastern amazon forest. Forest Sci. 57 (1), 51-58.

Dobriyal, P., Qureshi, A., Badola, R., Hussain, S.A., 2012. A review of the methods available for estimating soil moisture and its implications for water resource management. J. Hydrol. 458, 110-117.
Fan, J., Shao, M.A., Wang, Q.J., Jones, S.B., Klaus, R., Cheng, X.R., Fu, X.L., 2010. Toward sustainable soil and water resources use in China's highly erodible semi-arid loess plateau. Geoderma 155 (1-2), 93-100.

Gao, L., Shao, M.A., 2012. Temporal stability of soil water storage in diverse soil layers. Catena 95, 24-32.

Gao, X.D., Wu, P.T., Zhao, X.N., Zhang, B.Q., Wang, J.W., Shi, Y.G., 2013. Estimating the spatial means and variability of root-zone soil moisture in gullies using measurements from nearby uplands. J. Hydrol. 476, 28-41.

Gómez-Plaza, A., Martínez-Mena, M., Albaladejo, J., Castillo, V.M., 2001. Factors regulating spatial distribution of soil water content in small semiarid catchments. J. Hydrol. 253 (1-4), 211-226.

Grayson, R.B., Western, A.W., 1998. Towards areal estimation of soil water content from point measurements: time and space stability of mean response. J. Hydrol. 207 (1-2), 68-82.

Guber, A.K., Gish, T.J., Pachepsky, Y.A., van Genuchten, M.T., Daughtry, C.S.T., Nicholson, T.J., Cady, R.E., 2008. Temporal stability in soil water content patterns across agricultural fields. Catena 73 (1), 125-133.

Han, X., Li, X., Franssen, H.J.H., Vereecken, H., Montzka, C., 2012. Spatial horizontal correlation characteristics in the land data assimilation of soil moisture. Hydrol. Earth Syst. Sci. 16 (5), 1349-1363.

Heathman, G.C., Starks, P.J., Ahuja, L.R., Jackson, T.J., 2003. Assimilation of surface soil moisture to estimate profile soil water content. J. Hydrol. 279 (1-4), 1-17.

Hu, W., Si, B.C., 2014. Can soil water measurements at a certain depth be used to estimate mean soil water content of a soil profile at a point or at a hillslope scale? J. Hydrol. 516, 67-75.

Hu, W., Shao, M., Wang, Q., Reichardt, K., 2009. Time stability of soil water storage measured by neutron probe and the effects of calibration procedures in a small watershed. Catena 79 (1), 72-82.

Hu, W., Shao, M.A., Han, F.P., Reichardt, K., Tan, J., 2010a. Watershed scale temporal stability of soil water content. Geoderma 158 (3-4), 181-198.

Hu, W., Shao, M.A., Reichardt, K., 2010b. Using a new criterion to identify sites for mean soil water storage evaluation. Soil Sci. Soc. Am. J. 74, 762-773.

Hu, W., Shao, M., Han, F., Reichardt, K., 2011. Spatio-temporal variability behavior of land surface soil water content in shrub- and grass-land. Geoderma 162 (3-4), 260-272.

Hu, W., Tallon, L.K., Si, B.C., 2012. Evaluation of time stability indices for soil water storage upscaling. J. Hydrol. 475, 229-241.

Hu, W., Shao, M.A., Hou, M.T., She, D.L., Si, B.C., 2013. Mean soil water content estimation using measurements from time stable locations of adjacent or distant areas. J. Hydrol. 497, 234-243.

Jacobs, J.M., Mohanty, B.P., Hsu, E.C., Miller, D., 2004. SMEX02: field scale variability, time stability and similarity of soil water. Remote Sens. Environ. 92, 436-446.

Jia, X.X., Shao, M.A., Wei, X.R., Wang, Y.Q., 2013. Hillslope scale temporal stability of soil water storage in diverse soil layers. J. Hydrol. 498, 254-264.

Jiang, N., Shao, M.A., Hu, W., Wang, Y.Q., 2013. Characteristics of water circulation and balance of typical vegetations at plot scale on the Loess plateau of China. Environmental Earth Sciences 70 (1), 157-166.

Kachanoski, R.G., de Jong, E., 1988. Scale dependence and the temporal stability of spatial patterns of soil water storage. Water Resour. Res. 24, 85-91.

Lee, J.E., Oliveira, R.S., Dawson, T.E., Fung, I., 2005. Root functioning modifies seasonal climate. Proc. Natl. Acad. Sci. USA 102 (49), 17576-17581.

Liu, S.S., Roberts, D.A., Chadwick, O.A., Still, C.J., 2012. Spectral responses to plant available soil moisture in a Californian grassland. Int. J. Appl. Earth Obs. Geoinf. 19, 31-44.

Lu, Y.H., Fu, B.J., Feng, X.M., Zeng, Y., Liu, Y., Chang, R.Y., Sun, G., Wu, B.F., 2012. A policy-driven large scale ecological restoration: quantifying ecosystem services changes in the loess plateau of China. PLoS One 7 (2), e31782.

Markewitz, D., Devine, S., Davidson, E.A., Brando, P., Nepstad, D.C., 2010. Soil moisture depletion under simulated drought in the Amazon: impacts on deep root uptake. New Phytol. 187 (3), 592-607.

Martinez, G., Pachepsky, Y., Vereecken, H., Hardelauf, H., Herbst, M., Vanderlinden, K., 2013. Modeling local control effects on the temporal stability of soil water content. J. Hydrol. 481, 106-118.

Martínez-Fernández, J., Ceballos, A., 2003. Temporal stability of soil moisture in a large-field experiment in Spain. Soil Sci. Soc. Am. J. 67 (6), 1647-1656.

Mendham, D.S., White, D.A., Battaglia, M., McGrath, J.F., Short, T.M., Ogden, G.N., Kinal, J., 2011. Soil water depletion and replenishment during first- and early second-rotation Eucalyptus globulus plantations with deep soil profiles. Agric. For. Meteorol. 151 (12), 1568-1579.

Mohanty, B.P., Skaggs, T.H., 2001. Spatio-temporal evolution and time-stable characteristics of soil moisture within remote sensing footprints with varying soil, slope, and vegetation. Adv. Water Resour. 24 (9-10), 1051-1067.

Morbidelli, R., Corradini, C., Saltalippi, C., Flammini, A., Rossi, E., 2011. Infiltrationsoil moisture redistribution under natural conditions: experimental evidence as a guideline for realizing simulation models. Hydrol. Earth Syst. Sci. 15, 29372945.

Morbidelli, R., Saltalippi, C., Flammini, A., Rossi, E., Corradini, C., 2014. Soil water content vertical profiles under natural conditions: matching of experiments and simulations by a conceptual model. Hydrol. Process. 28 (17), 4732-4742.

Nelson, D.W., Sommers, L.E., 1982. Total carbon, organic carbon and organic matter. In: Page, A.L., Miller, R.H., Keeney, D.R. (Eds.), Methods of Soil Analysis, Part 2, second ed., Agronomy Monograph, vol. 4. ASA and SSSA, Madison, WI, pp. 534580 .

Nepstad, D.C., Decarvalho, C.R., Davidson, E.A., Jipp, P.H., Lefebvre, P.A., Negreiros, G.H., Dasilva, E.D., Stone, T.A., Trumbore, S.E., Vieira, S., 1994. The role of deep 
roots in the hydrological and carbon cycles of amazonian forests and pastures. Nature 372 (6507), 666-669.

Nosetto, M.D., Jobbagy, E.G., Paruelo, J.M., 2005. Land-use change and water losses: the case of grassland afforestation across a soil textural gradient in central Argentina, Glob. Change Biol. 11 (7), 1101-1117.

Nyberg, L., 1996. Spatial variability of soil water content in the covered catchment at Gardsjon, Sweden. Hydrol. Proc. 10 (1), 89-103.

Abdelkadir, A., Yimer, F., 2011. Soil water property variations in three adjacent land use types in the Rift Valley area of Ethiopia. J. Arid Environ. 75 (11), 1067-1071.

Pachepsky, Y.A., Guber, A.K., Jacques, D., 2005. Temporal persistence in vertical distributions of soil moisture contents. Soil Sci. Soc. Am. J. 69 (2), 347-352.

Penna, D., Brocca, L., Borga, M., Dalla Fontana, G., 2013. Soil moisture tempora stability at different depths on two alpine hillslopes during wet and dry periods. J. Hydrol. 477, 55-71.

Peterson, E.W., Wicks, C.M., 2006. Assessing the importance of conduit geometry and physical parameters in karst systems using the storm water management model (SWMM). J. Hydrol. 329 (1-2), 294-305.

Regalado, C.M., Ritter, A., 2006. Geostatistical tools for characterizing the spatial variability of soil water repellency parameters in a laurel forest watershed. Soil Sci. Soc. Am. J. 70 (4), 1071-1081.

Rosenbaum, U., Bogena, H.R., Herbst, M., Huisman, J.A., Peterson, T.J., Weuthen, A., Western, A.W., Vereecken, H., 2012. Seasonal and event dynamics of spatial soil moisture patterns at the small catchment scale. Water Resour. Res. 51 (1), 619638.

She, D.L., Shao, M.A., Timm, L.C., Sentis, I.P., Reichardt, K., Yu, S.E., 2010. Impacts of land-use pattern on soil water-content variability on the Loess Plateau of China. Acta Agric. Scand. Sect. B - Soil Plant Sci. 60 (4), 369-380.

Shi, H., Shao, M.A., 2000. Soil and water loss from the Loess Plateau in China. J. Arid Environ. 45, 9-20.

Steelman, C.M., Endres, A.L., Jones, J.P., 2012. High-resolution ground-penetrating radar monitoring of soil moisture dynamics: field results, interpretation, and comparison with unsaturated flow model. Water Resour. Res. 48.

Vachaud, G., Passerat de Silans, A., Balabanis, P., Vauclin, M., 1985. Temporal stability of spatially measured soil water probability density function. Soil Sci. Soc. Am. J. 49 (4), 822-828.

Vereecken, H., Huisman, J., Pachepsky, Y., Montzka, C., van der Kruk, J., Bogena, H., Weihermüller, L., Herbst, M., Martinez, G., Vanderborght, J., 2014. On the spatiotemporal dynamics of soil moisture at the field scale. J. Hydrol. 516 (76-96).
Wang, Y.Q., Zhang, X.C., Huang, C.Q., 2009a. Spatial variability of soil total nitrogen and soil total phosphorus under different land uses in a small watershed on the Loess Plateau, China. Geoderma 150, 141-149.

Wang, Z.Q., Liu, B.Y., Liu, G., Zhang, Y.X., 2009b. Soil water depletion depth by planted vegetation on the Loess Plateau. Sci. China, Ser. D Earth Sci. 52 (6), 835 842.

Wang, Y.Q., Shao, M.A., Shao, H.B., 2010. A preliminary investigation of the dynamic characteristics of dried soil layers on the Loess Plateau of China. J. Hydrol. 381 (1-2), 9-17.

Wang, Y.Q., Shao, M.A., Zhu, Y.J., Liu, Z.P., 2011. Impacts of land use and plant characteristics on dried soil layers in different climatic regions on the Loess Plateau of China. Agric. For. Meteorol. 151 (4), 437-448.

Wang, Y.Q., Shao, M.A., Liu, Z.P., Warrington, D.N., 2012. Regional spatial pattern of deep soil water content and its influencing factors. Hydrol. Sci. J. 57 (2), 265 281.

Wang, Y.Q., Shao, M.A., Liu, Z.P., 2013. Vertical distribution and influencing factors of soil water content within 21-m profile on the Chinese Loess Plateau. Geoderma 193-194, 300-310.

Western, A.W., Blöschl, G., 1999. On the spatial scaling of soil moisture. J. Hydrol 217 (3-4), 203-224.

Western, A.W., Blöschl, G., Grayson, R.B., 1998. Geostatistical characterisation of soi moisture patterns in the Tarrawarra catchment. J. Hydrol. 205 (1-2), 20-37.

Western, A.W., Grayson, R.B., Blöschl, G., 2002. Scaling of soil moisture: a hydrologic perspective. Annu. Rev. Earth Planet. Sci. 30, 149-180.

Western, A.W., Zhou, S.L., Grayson, R.B., McMahon, T.A., Bloschl, G., Wilson, D.J., 2004. Spatial correlation of soil moisture in small catchments and its relationship to dominant spatial hydrological processes. J. Hydrol. 286 (1-4), $113-134$.

Williams, A.G., Ternan, J.L., Fitzjohn, C., de Alba, S., Perez-Gonzalez, A., 2003. Soil moisture variability and land use in a seasonally arid environment. Hydrol. Process. 17 (2), 225-235.

Wu, T.N., Wang, Y.Q., Lv, J.W., Zhang, B., 2011. Soil water characteristics of middle pleistocene paleosol layers on the loess plateau. Afr. J. Biotechnol. 10 (53), 10856-10863.

Yang, L., Wei, W., Chen, L., Mo, B., 2012. Response of deep soil moisture to land use and afforestation in the semi-arid Loess Plateau, China. J. Hydrol. 475, 111-122.

Zucco, G., Brocca, L., Moramarco, T., Morbidelli, R., 2014. Influence of land use on soil moisture spatial-temporal variability and monitoring. J. Hydrol. 516, 193-199. 